\section{Gallstone Abscess due to Spilled Gallstones after Laparoscopic Cholecystectomy}

Sir,

Laparoscopic surgery has gained worldwide acceptance as gold standard treatment for symptomatic cholelithiasis. Although overall rate of complication is lower for laparoscopic cholecystectomy as compared to open cholecystectomy; the incidence of intraoperative gall bladder perforation is high, occurring in $15-33 \%$ of cases. ${ }^{1,2}$ Amongst gallbladder perforated cases, spillage of gall stones occurs in $16-66 \%$ of the cases. ${ }^{2}$ Retained intraperitoneal stones often appear to be clinically silent; but in rare cases, postoperative residual gallstones can contribute to abscess formation. ${ }^{3}$

A 60-year lady presented to Outdoor Surgical Department with 4-week history of pain in right hypochondrium, low grade fever, and loss of appetite. She had undergone laparoscopic cholecystectomy seven months back, which was uneventful, but no intraoperative notes were available. On examination, she was running temperature of $99^{\circ} \mathrm{F}$. She had tachycardia and was tender in right hypochondrium. Her ultrasound and CT scan abdomen revealed mass in right subphrenic space with an element of necrosis. This mass was having pressure effects over right lobe of liver. Based on these findings, a provisional diagnosis of right suphrenic abscess was made. Patient was operated via right subcostal incision. Loculated mass with necrotic material was present in the right subphrenic space (Figure 1).

To add to surprise, a stone measuring $2 \times 3 \mathrm{~cm}$ was found in the centre of loculated mass (Figure 2), which was probably slipped during previous cholecystectomy and acted as a nidus for subphrenic abscess. After drainage of the area, peritoneal toilet was done and abdomen was closed with placement of drains. Postoperatively, patient showed uneventful recovery and was discharged on 5th postoperative day with resolution of symptoms.

Gallstone abscess formed as a result of spilled gallstones is a rare complication following laparoscopic cholecystectomy. The case highlights the importance of keeping in mind gallstone abscess as a differential diagnosis when an abscess or fistula formation occurs even years after laparoscopic cholecystectomy. Most of these abscesses have been reported to manifest during the first 4 to 9 months after initial cholecystectomy; however, few can be detected as late as 15 years after laparoscopic cholecystectomy. 4 It is important that surgeon should remain vigilant about such possibility of lost gallstones during surgery. Every effort should be made to retrieve the spilled stones during laparoscopic

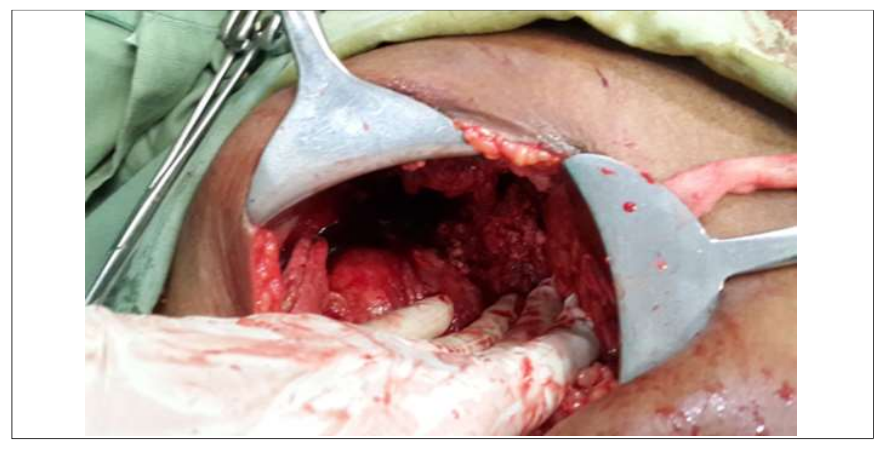

Figure 1: Necrotic debris and abscess in the right subphrenic space.

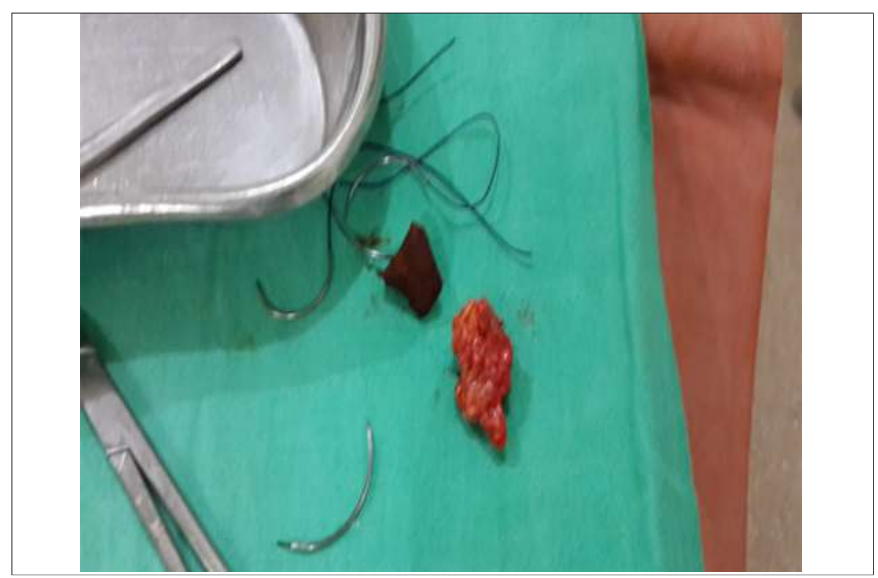

Figure 2: Retrieved stone from the abscess contents.

cholecystectomy in order to avoid such a rare but significant complication.

\section{REFERENCES}

1. Hui TT, Giurgiu DI, Margulies DR, Takagi S, lida A, Phillips EH. latrogenic gallbladder perforation during laparoscopic cholecystectomy: etiology and sequelae. Am Surg 1999; 65:944-8.

2. Uygar Kalayci M, Veli Akin B, Alis H, Kapan S, Nuray Turhan A, Aygun E. Short-term effects of gallbladder perforations during laparoscopic cholecystectomy on respiratory mechanics and depth of pain. Surg Endosc 2008; 22:1317-20.

3. Woodfield JC, Rodgers M, Windsor JA. Peritoneal gallstones following laparoscopic cholecystectomy. Surg Endosc 2004; 18:1200-7.

4. Arishi AR, Rabie ME, Khan MS, Sumaili $H$, Shaabi $H$, Michael NT, et al. Spilled gallstones: the source of an enigma. JSLS 2008; 12:321-5.

Sohail Saqib Chathal and Mahwish Farooq ${ }^{2}$

1 Department of Surgery, PAF Hospital, Lahore, Pakistan

2 Department of Obstetrics and Gynecology, Jinnah Hospital, Lahore, Pakistan

Correspondence: Dr. Sohail Saqib Chatha, Department of Surgery, PAF Hospital, Lahore, Pakistan

E-mail:drsohailchatha@hotmail.com

Received: August 01, 2018; Accepted: October 20, 2018

$$
\text { .......... }
$$

